\title{
$2-36$
}

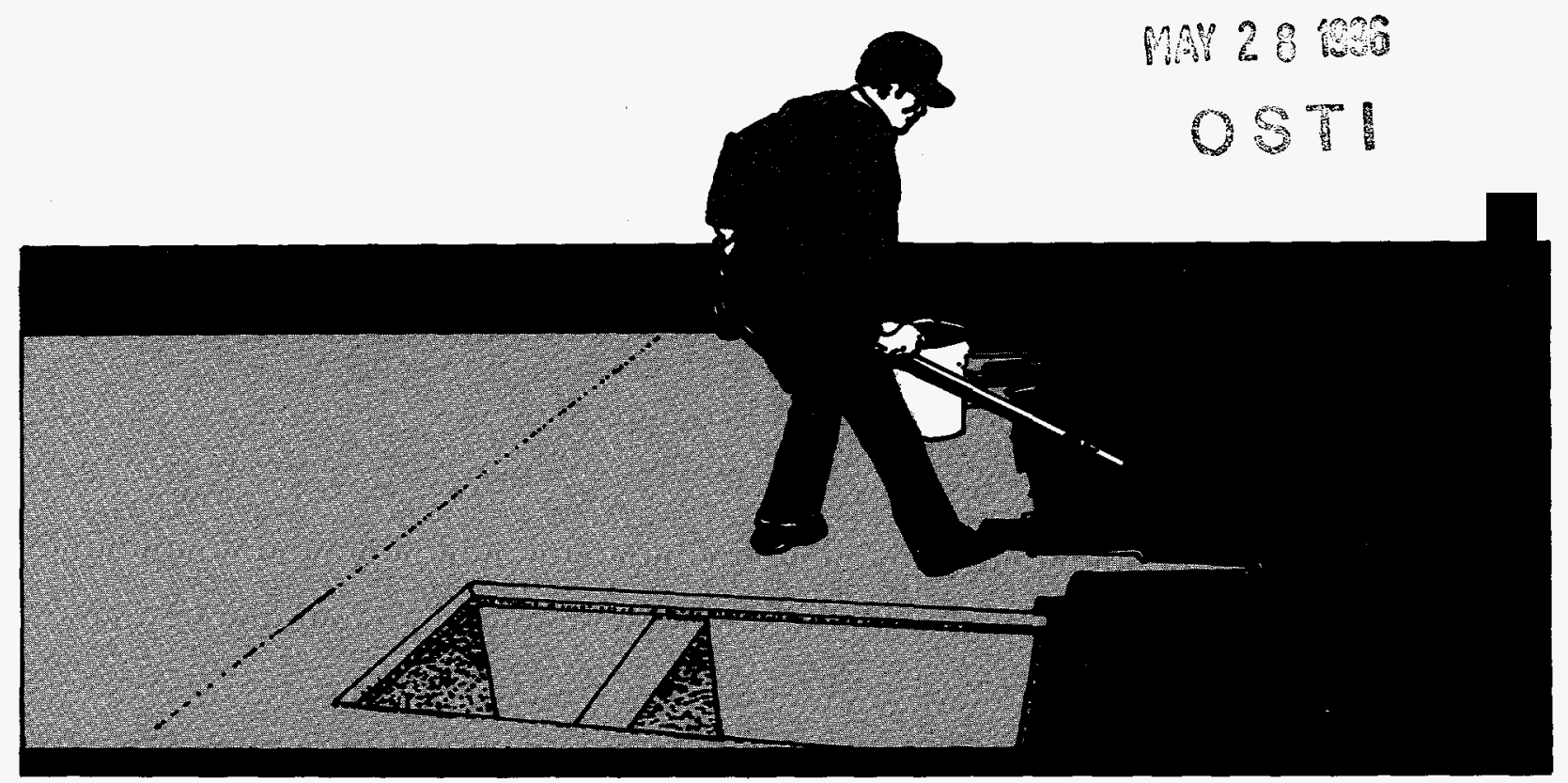

\section{Coating Concrete Secondary Containment Structures Exposed to Agrichemicals}

By: Michael F. Broder and Duy T. Nguyen

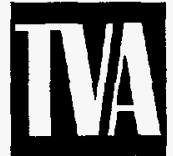

Tennessee Valley Authority

ENVIRONMENTAL RESEARCH CENTER

Muscle Shoals, Alabama 


\section{DISCLAMMER}

Portions of this document may be illegible in electronic image products. Images are produced from the best available original document. 


\section{Coating Concrete Secondary Containment Structures Exposed to Agrichemicals By: Michael F. Broder, Agricultural Engineer Duy T. Nguyen, Corrosion Specialist}

Land and Water Sciences ENVIRONMENTAL RESEARCH CENTER Muscle Shoals, Alabama 35662

June 1995

CONTENTS

INTRODUCTION 3 EFFECT OF PESTICIDES AND FERTILIZERS ON CONCRETE 4 CONCRETE AS A COATING SUBSTRATE 4 COATINGS 4 COATING PRACTICE 5 JOINTING PRACTICE 10 SUMMARY OF TVA/EPA COATING EVALUATIONS 11 COATING INSTALLATION COSTS 13 SUMMARY 14 DISCLAIMERS 14

REFERENCES 15 


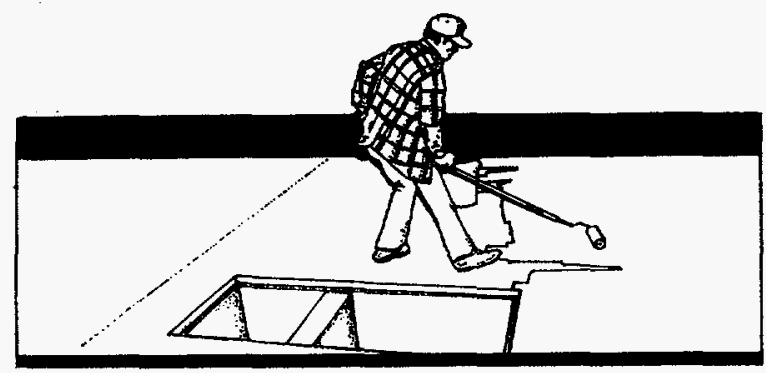

\section{INTRODUCTION}

Concrete has traditionally been the material of choice for building secondary containment structures because it is relatively inexpensive and has structural properties which make it ideal for supporting the loads of vehicles and large tanks. However, concrete's chemical properties make it susceptible to corrosion by some common fertilizers. Though fairly impervious to water movement, concrete is easily penetrated by vapors and solvents. It is also prone to cracking. For these reasons, the Environmental Protection Agency (EPA) believes that concrete alone may not provide an effective barrier to pesticide movement and has proposed that concrete in pesticide secondary containment structures be sealed or coated to reduce its permeability.

Some state secondary containment regulations require that concrete exposed to fertilizers and pesticides be sealed or protected with a coating. Lacking guidelines, some retailers have used penetrating sealants to satisfy the law, even though these products provide little protection from chemical attack nor do they prevent pesticide egress. Other retailers who have applied thick film coatings which were properly selected have had disastrous results because the application was poorly done. Consequently, much skepticism exists regarding the performance and benefit of protective coatings

The following discussion on concrete properties and successful coating practices is designed to assist those faced with the task of protecting their concrete secondary containment structures. Considerable information on successful coating practices is available from the National Association of Corrosion Engineers (1), the Steel Structures Painting Council, and the Coatings Technology Institute (2). The American Society of Testing Materials (3) also has guidelines for several aspects of concrete coating practices. 


\section{EFFECT OF PESTICIDES AND FERTILIZERS ON CONCRETE}

Concrete is easily corroded by some fertilizers and is easily penetrated by solvent-based herbicides. Specifications for water-tight concrete are given in several publications $(4,5,6)$. Concrete made by these specifications should resist damage due to freeze-thaw cycles and exposure to salts like potassium chloride. However, this concrete will still be susceptible to corrosion by urea-ammonium nitrate (UAN) solution and will still absorb herbicides.

In tests conducted by the TVA Environmental Research Center (7), UAN solution was corrosive to all the Portland cement-based concretes tested. Mixtures containing a micro-fine silica additive were superior to other mixtures, particularly in immersion tests, but still failed in drip tests. Only sulfur concrete survived UAN drip tests. Sulfur concrete is made of elemental sulfur (and some proprietary stabilizers) which is mixed with aggregate while molten.

The best use for a micro-fine silica additive appears to be in concrete exposed to mixtures of dry fertilizer. At one test site, silica modified concrete used in the working aisle of a dry blend plant was like new after five years. The ordinary concrete it had replaced was destroyed after four years.

Other studies at TVA's Environmental Research Center (7) revealed that herbicides penetrated concrete samples after five simulated spills despite being rinsed shortly after each spill. Penetration was so rapid that, 15 minutes after a spill, water was ineffective in removing the pesticide from inside the concrete. Four months after being contaminated, concrete samples still contained high levels of pesticides.

Also, concrete cylinders immersed in herbicides for 90 days lost about 50 percent of their compressive strength (8). Therefore, concrete coming in frequent contact with herbicides or UAN solution needs to be protected.

\section{CONCRETE AS A COATING SUBSTRATE}

Successful coating of concrete requires a basic knowledge of the properties of the concrete as well as the coating. Unlike steel, which is impervious, concrete is quite porous and has a relatively low tensile strength. As a rule, concrete's tensile strength is about one-tenth of its compressive strength. A typical concrete with a compressive strength of $3,000 \mathrm{psi}$ would have a tensile strength of only 300 psi. An epoxy coating on this concrete could achieve an adhesive strength of only $300 \mathrm{psi}$, but the same coating on a steel surface could achieve a strength of $1,500 \mathrm{psi}$.

To achieve the maximum bond strength of coating on concrete, the concrete has to be free of contaminants and surface laitance. Laitance is a film that can form on the surface of concrete during placement. Ranging from a few mils to one-fourth inch in thickness, laitance is unreacted material or cement made weak by bleed water which is not removed from the surface during placement.

When dry, the void volume of concrete ranges from 10 to 25 percent. Air moves in and out of concrete with changes in temperature and barometric pressure. Air passing out of concrete can cause pinholes to form in the cured coating or can be trapped under freshly applied coatings causing the coating to blister (form gaseous pockets between the substrate and coating).

Also, moisture in concrete can cause some coatings to disbond or become soft. Water, which exerts a vapor pressure, can also cause a coating to blister.

\section{COATINGS}

Coatings generally are formed by a mixture of solids and liquids. The liquid portion is called the coating vehicle and consists of volatile liquids and solids which remain after the volatiles have evaporated. Coating manufacturers describe coatings by their percent solids. That is, the percentage of the material that is nonvolatile. The percent solids of a coating defines how much the coating will shrink as it cures. A 50-percent-solids coating will shrink 50 percent while curing. That is, its dry film thickness (DFT) will be 50 percent of its wet film thickness (WFT). Some air pollution regulations restrict the 
use of coatings with high amounts of volatile organics. Consequently, the development of coatings with high-solids content is a high priority for the coatings industry.

Coatings are often described in terms of film thickness. A thin film has a final dry film thickness of less than 20 mils ( 1 mil is $1 / 1,000$ th of an inch). Thin films are generally used for decoration and for protection against mild chemicals. Thin films are usually not continuous over rough concrete surfaces. Thus, thin films, with the pinholes and defects often present, provide little protection to concrete. Thick films have a final dry thickness of 20 to 80 mils and often are applied in layers, forming a film free of defects. Thick films are required for protection of concrete in harsh environments.

The volume of coating required for a particular job is a function of both solids content and film thickness. The equation for calculating coverage rates is:

$$
\mathrm{G}=\frac{\mathrm{A} \times \mathrm{DFT}}{1,604 \times \mathrm{S}}
$$

In this equation, $G$ is the amount of coating to be used in gallons, $A$ is area to be covered in square feet, DFT is the average dry film thickness in mils, and $S$ is the percent solids by volume of the coating (represented by a fractional value instead of percent).

On a smooth surface, one gallon of a 100-percentsolids coating will cover 1,604 square feet at one-mil thickness. The same coating will cover about 80 square feet at a thickness of 20 mils. A coating with a solids content of 50 percent will cover one-half the area of a 100-percent-solids coating.

A number of generic types of coatings are available. The most common ones used in secondary containment are epoxy, polyurethane, vinyl ester, and polysulfide. A number of other coatings, such as acrylics, vinyls, and silicones, will not be discussed here because they are not resistant to organic solvents commonly found in pesticides.

Epoxies and polyurethanes are popular because they can be formulated a number of ways to enhance particular properties. Epoxies are among the best coatings because they have good chemical and moisture resistance, shrink little during curing, and adhere well to concrete. Their main disadvantage is that they are not resistant to ultraviolet radiation requiring a UV resistant finish coat.
Polyurethanes have good chemical and UV resistance but generally do not adhere as well to concrete as do other coatings. An initial coating of primer is often needed to improve the bonding of polyurethanes to concrete.

Vinyl ester has long been the coating of choice for acid service. This product also has excellent resistance to solvents. Vinyl ester's primary disadvantages are that it is very moisture sensitive and it has a short shelf life.

Polysulfide is a flexible material which has been used for years as a joint sealant. It has good chemical resistance but has a low tensile strength and low abrasion resistance. Consequently, it is not well suited for areas exposed to mechanical stresses. Formulations with epoxy or epoxy novolac added to the polysulfide have mechanical properties superior to polysulfide alone and are designed for abrasive service.

An important coating property to consider is pot life. Pot life is the length of time a coating will remain fluid after being mixed. Some coatings have such a short pot life that the two parts must be mixed at the spray nozzle. Most generally have a pot life of 30 minutes to 2 hours, depending on ambient conditions. Care must be taken to mix only as much as can be applied before the mix begins to set.

\section{COATING PRACTICE}

As alluded to earlier, concrete is not an ideal material for coating because it is porous and has low tensile strength. The failure of coatings is due primarily to improper preparation of the concrete surface. One report suggests that up to 70 percent of concrete coating failures result from poor surface preparation. Before application of a coating, the concrete surface should be prepared to effect the best adherence and provide the most continuous coverage of the coating to the concrete.

Concrete to be coated should have a light broom or wooden trowel finish. Steel trowels, particularly powered ones, leave the surface too smooth for good coating adhesion. Formed vertical surfaces are generally too rough and have voids (bugholes) that require patching prior to coating.

Coatings can fail by delaminating (separating by layers) or by separating from the concrete. The most 


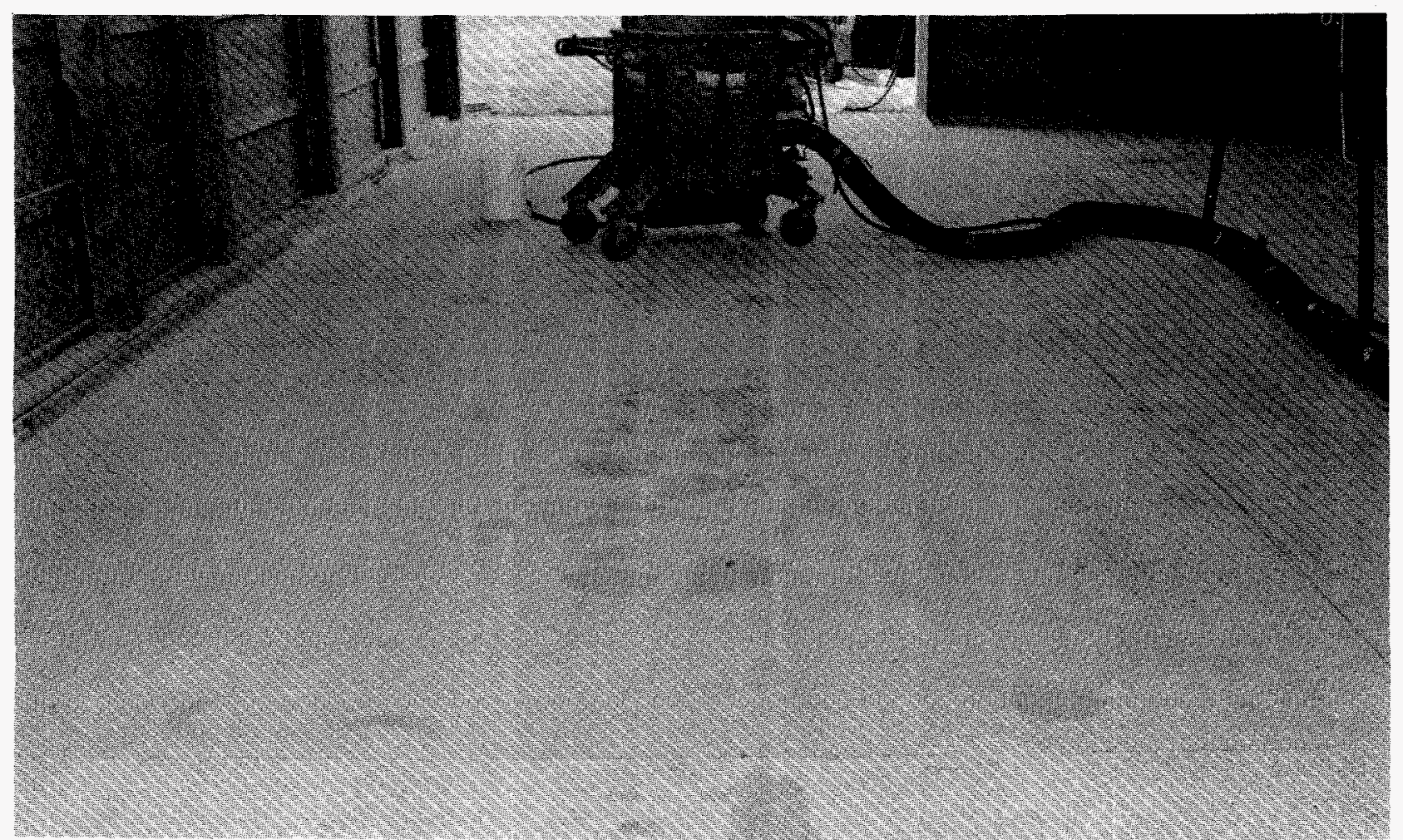

Lines show the paths made by the centrifugal blasting machine. Oil which has penetrated beneath the etched surface will be removed with solvent.

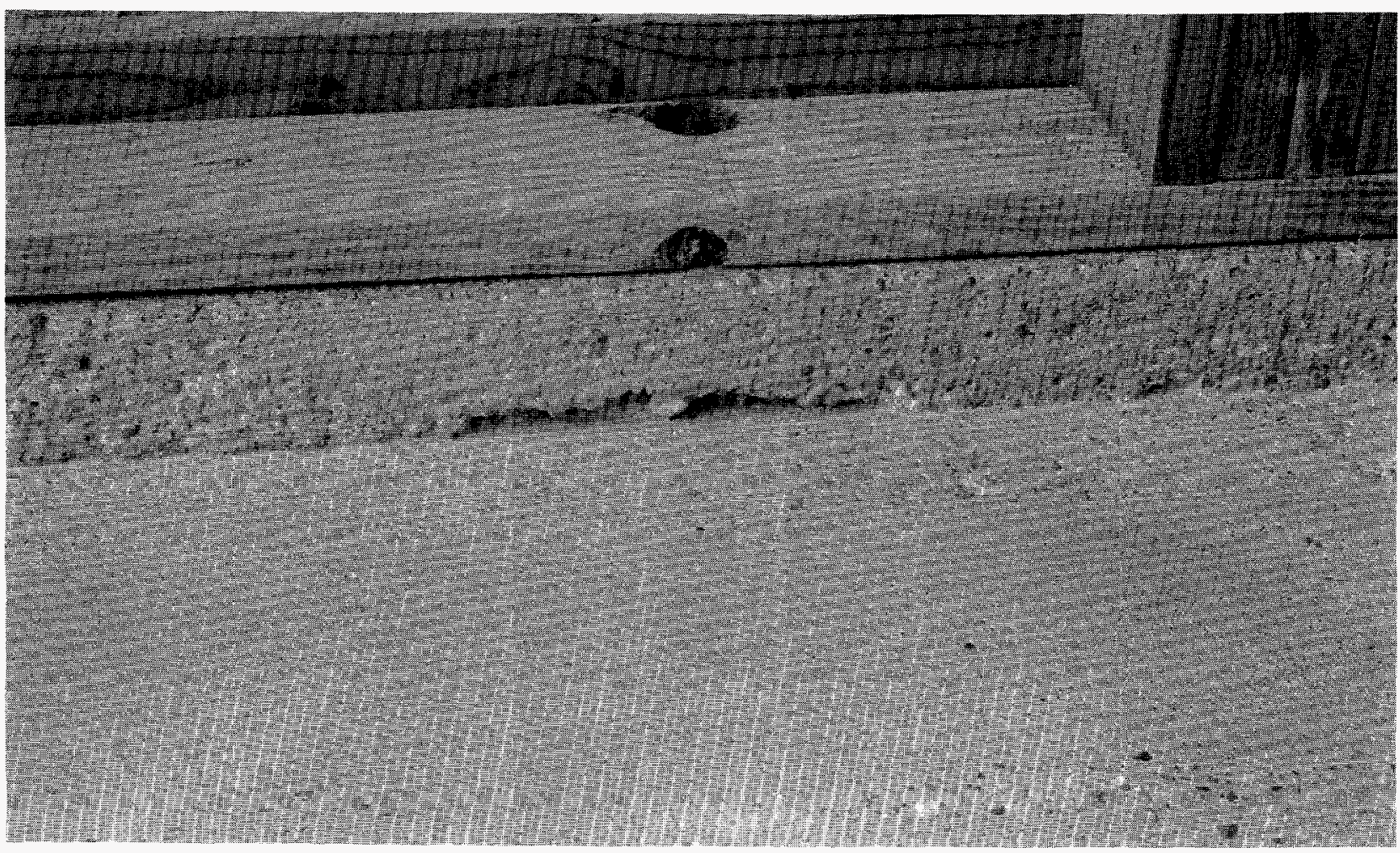

Surface preparation can open up voids and bugholes on formed surfaces which must be filled with a patching material before applying a coating. 


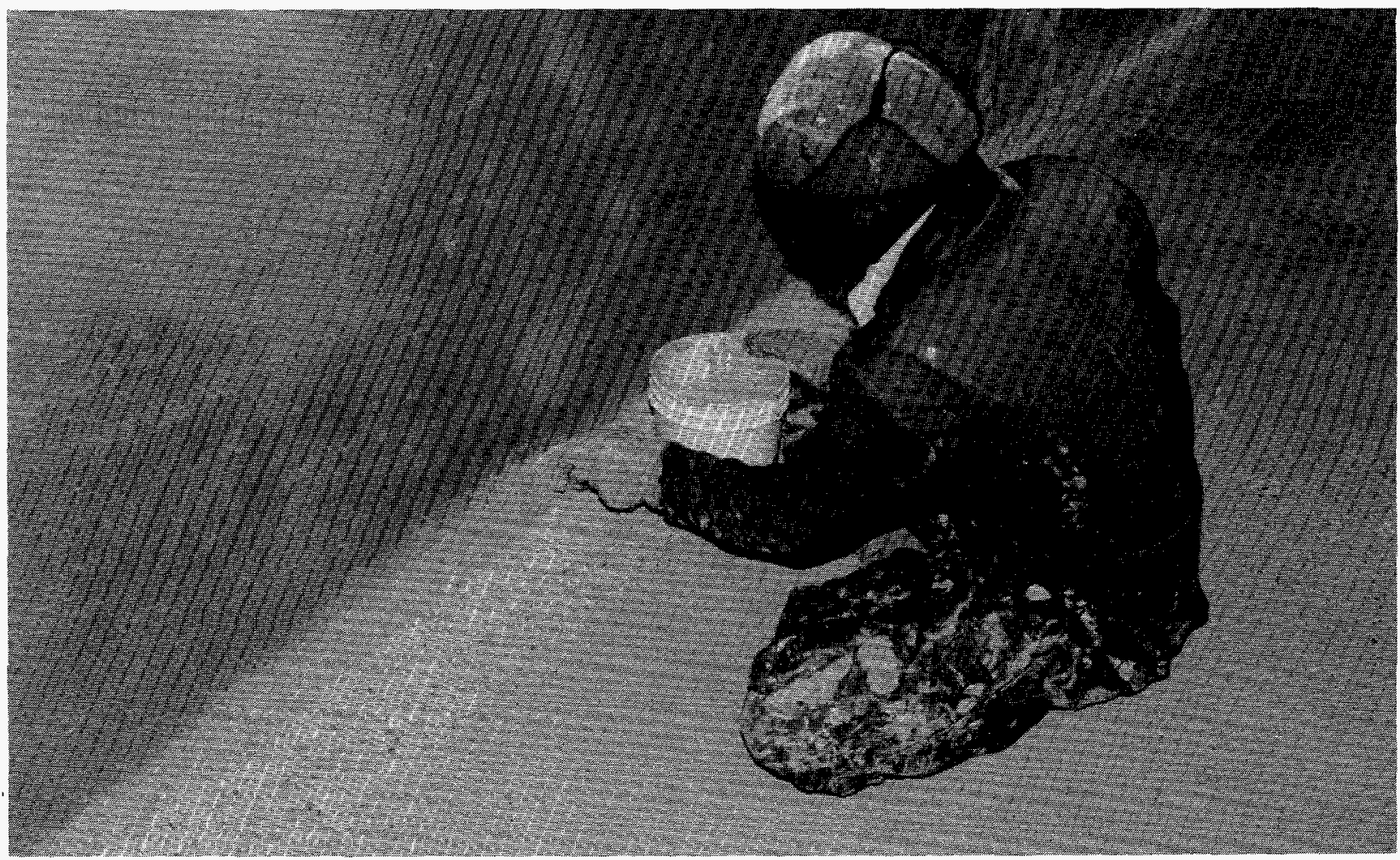

An epoxy-based patching material, supplied by the coating manufacturer, is being used to fill bugholes.

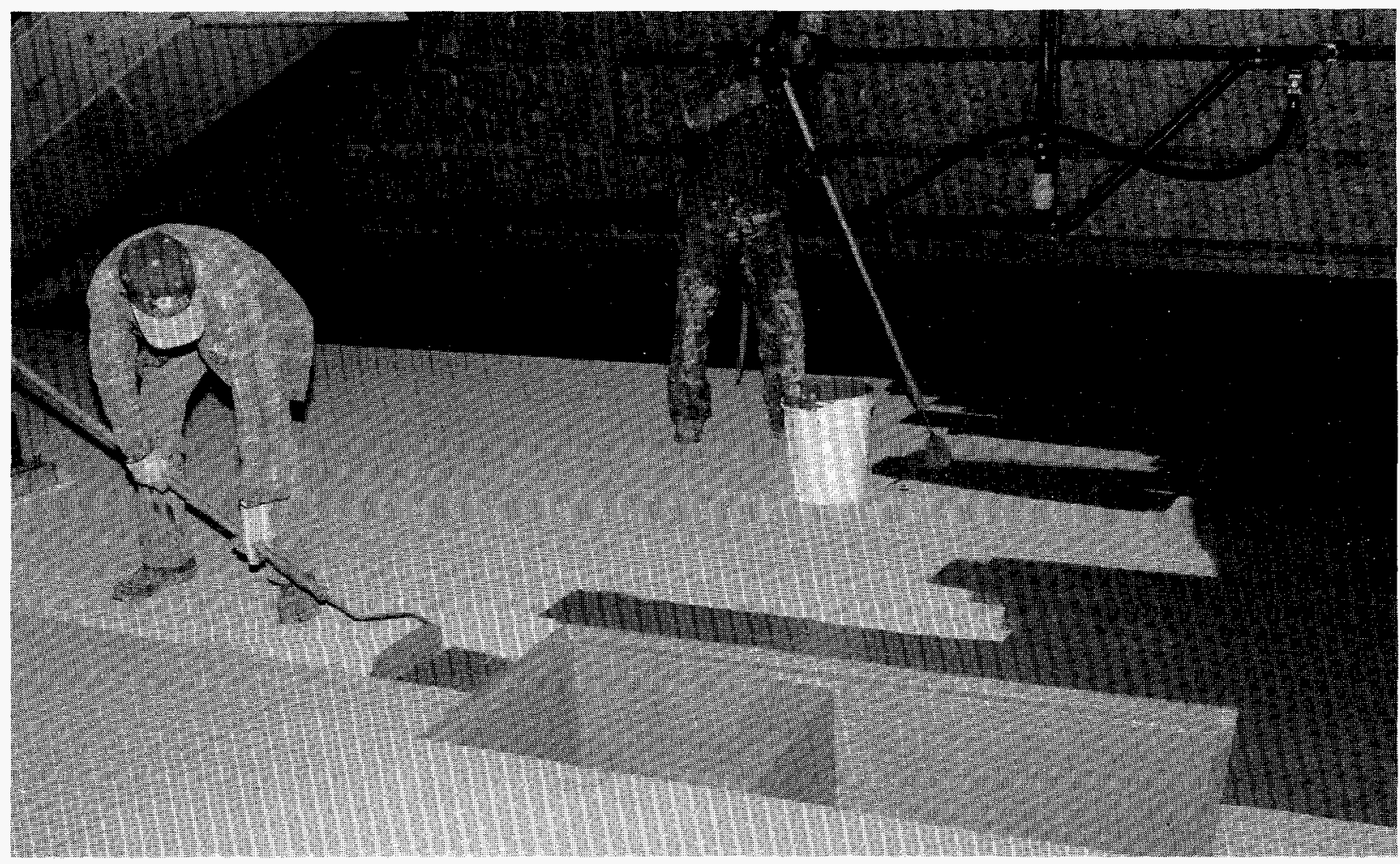

The first layer of coating is being applied in the evening after the concrete surface temperature has peaked. 


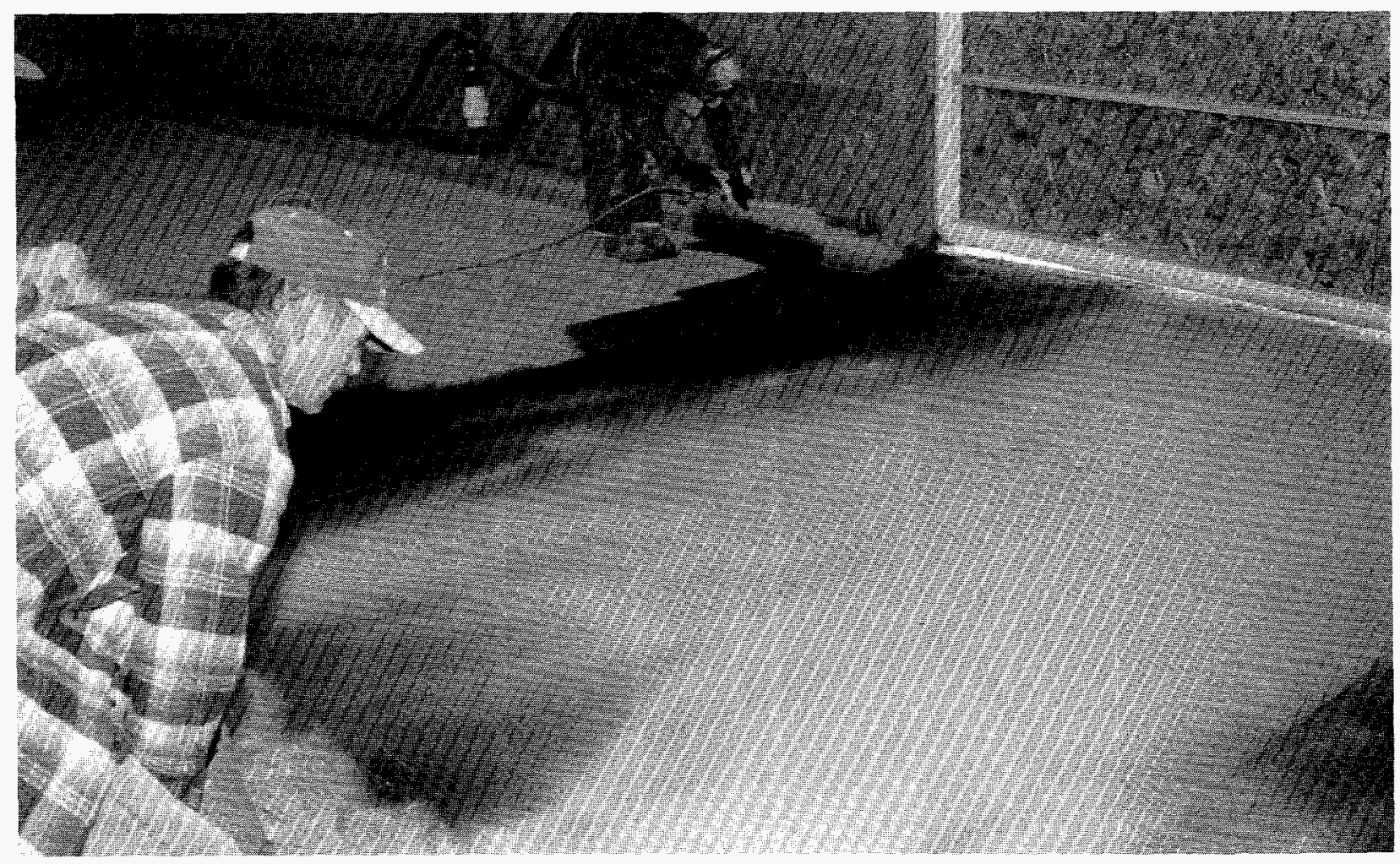

To produce a non-skid surface, sand is broadcast immediately after rolling on the first layer of coating.

common form of coating separation from concrete, however, is substrate failure. This occurs when the coating separates from the concrete and takes a portion of the concrete with it. Substrate failure is due to a loss of integrity of the concrete at the adhesive interface. This type of failure can occur when coatings are applied without first removing the surface laitance.

No industry-wide standards have thus far been adopted and considered mandatory for the preparation and coating of concrete surfaces. However, the American Society of Testing Materials (ASTM) has prepared a set of documents which suggest standard practices for many aspects of this facet of construction. For example, concrete should be allowed to cure and be completely dry prior to coating application. The ASTM D 4263, Test Method for Indicating Moisture by the Plastic Sheet Method, is one standard indicator of concrete dryness, and the Delmhorst moisture meter is another method for determining moisture content in concrete.

Loose or unsound surface materials should be removed in order to provide a sound substrate.
Furthermore, absorbed contaminants, such as oil or organics, should be removed because they frequently interfere with adhesion of the coating to the surface. And, surface preparation often opens up cracks and voids at or just below the surface. Excessively rough surfaces must be repaired before application of the coating.

Also, surface defects, such as mildly spalling concrete, cracks, and bugholes, must be repaired prior to coating. These defects cause blistering, poor adhesion to the surface, and/or discontinuity of the film. Repair of concrete surface defects is generally required before and/or after other methods of surface preparation are performed.

The repair of surface defects is normally done using a patch material. This patch material is generally a cementitious or an organic resin-based material recommended for a particular coating system, type of concrete, and defects. The patching material recommended by the coating manufacturers should be used; otherwise the coating may not adhere well to the patching material. 
Portland cement-based patching materials may be adequate for patching concrete; however, cementbased materials may separate from the substrate after coating because of internal stress. If cement-based patching materials are deemed adequate, considerable skill will be required in proportioning the water and mortar. Also, a 7-day wet curing will be necessary to prevent patches from shrinking.

When dealing with cracks, one must determine if the cracks are moving or fixed. If small enough, fixed cracks can be bridged or filled. Moving cracks may have to be treated as expansion joints.

There are a number of methods for preparing the concrete surface to accept a coating. The most common method is sandblasting. In areas where the dust from sandblasting would present problems, wet abrasive blasting can be employed, or, centrifugal blasting equipment which collects dust and removed concrete while recycling the steel aggregate can be used. Other mechanical preparation machines which have teeth or sharpened tools also can be used effectively. And, water at extremely high pressure can be used to prepare concrete surfaces.

Acids, generally muriatic acid, can be used to etch concrete surfaces prior to coating. Acid etching is not the preferred method of surface preparation because it is not suitable for vertical surfaces and because the acid can further attack the concrete if not properly neutralized. ASTM standard methods D 4260, Standard Practice for Acid Etching Concrete, and D 4262, Test Method for pH of Chemically Cleaned or Etched Concrete Surfaces, should be followed for best results.

Regardless of the coating to be applied, some type of surface preparation is required to achieve the surface profile necessary for good coating adhesion.

Environmental conditions during coating application can have a significant effect on the performance of the coating. Concrete surface temperature, ambient temperature, and relative humidity should be monitored, and, if necessary, adjusted to adhere to recommendations of manufacturers. Most coatings will not cure below 50 degrees $F$. And below 70 degrees $F$, coatings may require over a week to cure. For cold weather applications, low temperature coatings should be considered. Some coatings can be applied to concrete at temperatures down to 35 degrees $F$.
Propane-fired heaters are commonly used to raise the temperature of concrete and the surrounding air. Space heaters that burn kerosene (salamanders) should not be used because their exhaust will leave a residue that can cause the coating to blister. While the coating is being applied, heat from space heaters may need to be ducted into the area to avoid igniting any volatile solvents.

As a rule, the first coat of material on the concrete should be applied at a concrete surface temperature of at least 15 degrees $F$ above the dewpoint.

Subsequent coats can be applied to a surface temperature 5 degrees above dewpoint. These constraints make it difficult to coat exterior concrete in the Midwest between the fall and spring seasons.

In outside applications, the first coat of material should be applied in the afternoon after the maximum concrete surface temperature has been reached. This will eliminate the tendency for expanding air in pore space to exit through the coating causing bubbling and pinholes. Pinholes that form in the first layer will continue through subsequent layers if coatings are applied while concrete temperature is rising.

Application of the coating must be done properly to ensure good protection of the substrate and a long coating life. The application method must provide a continuous film of protection which has a relatively constant thickness and adheres strongly to the substrate.

Brushes and rollers often are used to apply coatings. Rollers require the least amount of skill but do not provide adequate coverage in difficult areas. Some extremely viscous coatings must be trowel applied. Some skill is required to form uniform coatings by trowelling and this is by far the slowest application technique.

Spraying is the method of choice for application of coatings. Spray application requires personnel with considerable skill in the use of spray equipment. The spray gun must be adjusted to form the correct spray pattern. Proper application techniques, including proper angle and direction of spraying, proper stroke motion and direction, and special methods for spraying difficult areas, must be practiced. Time-consuming cleaning and maintenance are essential to providing precise functioning equipment and avoiding blockage. 
Coating manufacturers' recommendations should be followed regarding details for spray application.

Considerable skill is required to successfully coat concrete. Though manufacturers strive to make coatings versatile and simple to use, considerable attention to detail is needed to ensure success. Manufacturers' recommendations should be followed closely. And those who are not experienced in coating concrete may want to secure the services of a certified applicator. If the coating is applied by a certified applicator, some coating manufacturers will guarantee the coating for one to five years.

\section{JOINTING PRACTICE}

Since concrete shrinks during drying and expands and contracts with temperature changes, steel reinforcement and expansion (control) joints are needed to control cracking. In un-reinforced concrete slabs, control joints should be spaced no further apart than 30 times the slab thickness. Sections between joints should be square; if not square, the length-to-width ratio should be no more than 1.5. In reinforced floors, joints are usually spaced 15 to 25 feet. Wall joints should be in line with floor joints. Sumps, troughs, and column supports should be isolated from the slab with control joints.

Joints can be formed during placement of concrete or cut after the concrete is set but before shrinkage occurs. Cuts should be made within 12 hours of the

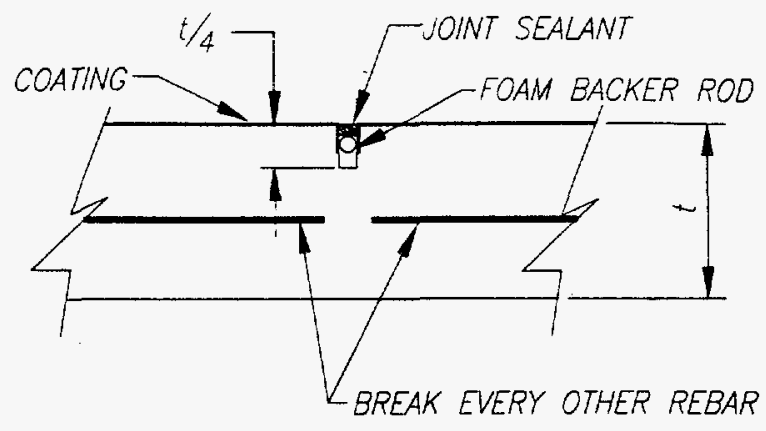

Figure 1. Sawn floor control joint. Sides of joint are coated to ensure that all concrete is protected. pour to prevent shrinkage cracks. The cut should be about one-fourth the depth of the slab.

There are three ways to seal control joints, and two of the methods can be used to seal active cracks. The simplest method is to place a bond breaker in the joint and use a chemically resistant joint sealant. The width-to-depth ratio of the sealant should be 0.5 . The bond breaker is needed to prevent the sealant from tearing when the joints expand (see figure 1). On a coated floor, the sides of the joint should be coated before the bond breaker and flexible sealer are installed. Cracks can be routed to achieve a rectangular cross-section and sealed by this method.

The second way to seal joints is to install a waterstop before pouring the concrete. Joints are then made above the waterstop and sealed as described above (see figure 2). The waterstop provides a second seal if the sealant in the joint fails.

The third method of sealing a joint is often used to prepare cracks. A disbonding tape, 2 inches wide, is placed over the crack or joint, and then a coating reinforced with fiberglass is placed over the crack, forming a bridge over the tape. Unless a flexible coating is used on top, this type of crack bridging system will only work for cracks with little movement.

More information on joint sealing is available from the American Concrete Institute (8).

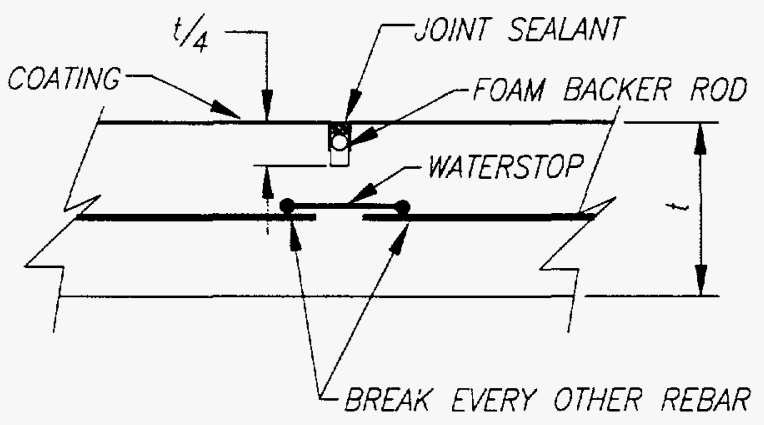

Figure 2. Control joint with waterstop. Waterstop must be accurately placed before concrete is poured. 


\section{SUMMARY OF TVAIEPA}

\section{COATINGEVALUATIONS}

A study was conducted at the TVA Environmental Research Center, Muscle Shoals, Alabama, to determine the performance of concrete and various organic coatings used in containment structures designed to hold bulk agricultural pesticides. All the laboratory tests with coatings have been described in detail in reference (9). An interim report which lists some coating costs is available from the TVA Bookstore (10).

Two types of tests were conducted. In the first series, free films of coatings were immersed in formulated pesticides for 21 days and then examined for change in weight, strength, elasticity, and hardness. In the second series, concrete cylinders were coated and immersed in chemicals for 90 days. In the second series, only the four best coatings identified in the first series were tested.

The 12 coatings tested as free films are listed in Table 1. The generic description, recommended dry film thickness, and performance rating are included in the listing.
The test chemicals are listed in table 2. These products were chosen from a list of the 27 most common bulk products used in the United. States. The list of 27 was reduced to 9 by eliminating some aqueous solutions, mixtures, and products with similar chemistry. Some aqueous solutions were eliminated because they are less reactive than are solvent-based products. The insecticide, dimethoate 'trade name Cygon) was added at the request of EPA who felt that at least one insecticide should be tested. Cygon was chosen because it contains a solvent that penetrates and softens certain plastics. Results of the study indicate that, in terms of the effect that pesticides have on concrete and coatings, these findings represent the extremes that would be seen at retail agrichemical sites.

The performance of the 12 coatings can easily be divided into three categories: excellent, adequate, and unsatisfactory.

Coatings that were found unsatisfactory absorbed such high amounts of some solvent-based pesticides that they swelled excessively, became very soft, and lost practically all their tensile strength. Some coating films degraded so badly that they could not

TABLE 1

COATING TYPE, MINIMUM DRY FILM THICKNESS, AND PERFORMANCE RATING

\begin{tabular}{|l|c|l|}
\hline \multicolumn{1}{|c|}{ Coating Type } & \multicolumn{1}{|c|}{$\begin{array}{c}\text { Minimum Dry Film } \\
\text { Thickness }\end{array}$} & Performance Rating \\
\hline Flake Filled Epoxy Novolac & 20 & Excellent \\
\hline Polysiloxane Epoxy & 20 & Excellent \\
\hline Flake Filled Vinyl Ester & 30 & Excellent \\
\hline Epoxy Phenolic Resin & 15 & Excellent \\
\hline $100 \%$ Solid Epoxy Phenolic & $60^{2}$ & Excellent \\
\hline $100 \%$ Solid Polyamide Cured Epoxy & 20 & Adequate \\
\hline $90 \%$ Solid Epoxy & 12 & Adequate \\
\hline Amido-Amine Cured Epoxy & 12 & Adequate \\
\hline Polysulfide Epoxy & 20 & Unsatisfactory \\
\hline Elastomeric Polysulfide & 30 & Unsatisfactory \\
\hline Urea Urethane & 60 & Unsatisfactory \\
\hline Aromatic Urethane Elastomer & 20 & Unsatisfactory \\
\hline
\end{tabular}

a. Thickness includes aggregate filler for non-skid surface. 
TABLE 2

PESTICIDES USED IN TVA/EPA COATING STUDY ${ }^{\mathrm{a}}$

\begin{tabular}{|c|c|c|c|}
\hline Product Name & Common Name & Formulation & Company \\
\hline Atrazine & Atrazine & Flowable liquid & Ciba-Geigy \\
\hline Basagran & Bentazon & Soluble concentrate & BASF \\
\hline Command & Clomazone & Emulsifiable concentrate & FMC \\
\hline Dual & Metolachlor & Emulsifiable concentrate & Ciba-Geigy \\
\hline Eradicane & EPTC-thiocarbamate & Emulsifiable concentrate & ICI Americas \\
\hline Lasso & Alachlor & Emulsifiable concentrate & Monsanto \\
\hline Prowi & Pendimethalin & Emulsifiable concentrate & American Cyanamid \\
\hline Squadron & $\begin{array}{r}\text { Imazaquin }+ \\
\text { Pendimethalin }\end{array}$ & Emulsifiable concentrate & American Cyanamid \\
\hline Treflan & Trifluralin & Emulsifiable concentrate & Dow-Elanco \\
\hline Cygorl & Dimethoate & Emuisifiable concentrate & American Cyanamid \\
\hline
\end{tabular}

a. Information from Farm Chemicais Handbook (13) and The Agrochemicals Handbook (14)

b. Cygon was included at EPA's request so that an insecticide would be tested.

TABLE 3

AVERAGE WEIGHT CHANGE OF COATING FILMS AFTER 21-DAY IMMERSION

\begin{tabular}{|c|c|c|c|c|c|c|c|c|c|c|c|}
\hline & \multicolumn{11}{|c|}{ PESTICIDES/FERTILIZER } \\
\hline COATING TYPE & Atrazine & Basagran & Command & Dual & Eradicane & Lasso & Prowl & Squandron & Treflan & Cygon & UAN \\
\hline 1. Polysilorane" & 1.9 & $\mathbf{N} / \mathbf{A}$ & -0.7 & -1.3 & $\mathbf{N} / \mathbf{A}$ & N/A & N/A & 1.4 & N/A & -1.6 & -1.0 \\
\hline 2. Epoxy Novolac & 1.2 & 0.9 & $\overline{0.3}$ & 0.2 & 0.1 & 0.2 & 0.5 & 1.7 & 0.3 & 0.0 & 0.3 \\
\hline 3. Vinyl Eoter & 0.4 & 0.3 & 0.1 & -0.4 & -0.3 & 0.4 & 1.3 & 1.8 & -0.1 & 0.4 & 0.1 \\
\hline $\begin{array}{l}\text { 4. } 100 \% \text { Soldd } \\
\text { Epoxy }\end{array}$ & 1.1 & N/A & $\overline{6.0}$ & 0.1 & $\mathbf{N} / \mathbf{A}$ & $\mathbf{N} / \mathbf{A}$ & $\bar{N} / \mathbf{A}$ & 5.9 & N/A & 6.5 & 0.3 \\
\hline 5. Epoxy Phenolic & -1.5 & -1.6 & -1.1 & -0.9 & -1.4 & -0.5 & 2.1 & 1.7 & -1.4 & 6.3 & 0.0 \\
\hline $\begin{array}{l}\text { 6. } 100 \% \text { Solid } \\
\text { Polyamide-Cured } \\
\text { Epoxy }\end{array}$ & 1.0 & N/A & 5.5 & 0.4 & N/A & $\mathrm{N} / \mathrm{A}$ & N/A & 10.8 & $\mathbf{N} / \mathbf{A}$ & 11.6 & 0.4 \\
\hline 7. $90 \%$ solid Epoxy & -3.1 & $\mathbf{N} / \mathbf{A}$ & 11.9 & -2.9 & N/A & $\mathbf{N} / \mathbf{A}$ & $\mathbf{N} / \mathbf{A}$ & 3.6 & $\mathbf{N} / \mathbf{A}$ & 5.7 & -2.7 \\
\hline $\begin{array}{l}\text { 8. Amido-Amine } \\
\text { Cured Epoxy }\end{array}$ & 1.6 & $\mathrm{~N} / \mathrm{A}$ & 29.2 & 0.6 & $N / A$ & N/A & N/A & 11.4 & N/A & 41.4 & 0.3 \\
\hline 9. Polysulfide Epoxy & -0.4 & N/A & 51.3 & 1.7 & $\mathbf{N} / \mathbf{A}$ & $\mathbf{N} / \mathbf{A}$ & N/A & 24.0 & N/A & 84 & -0.5 \\
\hline 10. Urea Urethane & 1.0 & 0.7 & 42.1 & 5.5 & 30.6 & 30.8 & 17.1 & 15.9 & 4.0 & 98.0 & 0.1 \\
\hline II. Urethane & 0.4 & 2.6 & 24.8 & 27.2 & 12.0 & 8.5 & 9.0 & 17.2 & 13.3 & 103 & 0.6 \\
\hline 12. Polysulfide & 3.8 & -0.2 & 59.5 & 84.5 & 21.6 & 57.6 & 44.9 & 54.9 & 10.7 & $-100^{8}$ & 0.0 \\
\hline
\end{tabular}

$\mathrm{N} / \mathrm{A}=$ Coating was not tested in this chemical.

a. Coatings in bold print were considered excellent.

b. Coatings in normal print were adequate.

c. Coatings italicized were unsatisfactory.

d. Films could not be retrieved from Cygon. 
be retrieved for mechanical tests. The four unsatisfactory coatings were flexible (elastomeric). Although this is a desirable quality for bridging cracks, flexible coatings generally are not solvent resistant.

Those coatings that were found to be adequate absorbed some pesticide but remained intact with some change in strength.

Coatings were considered excellent if they had negligible weight increases and only small changes in their mechanical properties.

The four coatings found to be excellent in the 21-day immersion tests were used to coat concrete cylinders for the second series of tests. The epoxy novolac and polysiloxane epoxy were slightly better than the vinyl ester and phenolic epoxy in these 90-day immersion tests.

Table 3 lists the percent change in weight of the films after being immersed in pesticide for 21 days. Negative values denote a loss in weight while positive values indicate that the films absorbed pesticides, inert solvents, or both.

Papers by Fisher (11) and Fisher and Carpenter (12) state that coatings are acceptable for immersion service if they neither increase in weight by more than 10 percent nor lose weight after a 30-day exposure. Products meeting these criteria were considered excellent (bold print). Those which failed these weight change criteria but remained intact were considered satisfactory (regular print), and those with severe weight increases were considered unsatisfactory (italicized print).

All of the coatings performed well in UAN solution.

\section{COATING \\ INSTALLATION COSTS}

The costs associated with the installation of a coating are site specific and difficult to estimate. In concrete coating work, the cost of surface preparation usually exceeds the cost of the coating. Considerable savings can be realized by properly designing and finishing the structure to be coated. Estimates given here are based on contractor installations. Agrichemical retailers can lower their coating installation costs by doing it themselves; however, they have no recourse if the coatings fail prematurely.

Coating installation costs can be broken into four categories: mobilization, surface preparation, coating materials, and application cost.

Mobilization Costs: The costs associated with transporting the people and equipment required to perform a coating installation are the mobilization costs. Since small jobs require much of the same equipment and personnel as large jobs, mobilization costs for small jobs can be relatively high. Unless a local contractor can be used, lodging costs are unavoidable, since most installations usually involve two coats and/or a primer coat and each must cure overnight. Depending on job size, mobilization costs can range from $\$ 0.10$ to $\$ 0.50$ per square foot of coating.

Surface Preparation Costs: Surface preparation costs can range from $\$ 0.50$ to $\$ 2.00$ per square foot, depending on the geometry of the structure and the amount of patching and decontamination required. Costs are lowest for new, flat floors that can be prepared with powered equipment. Formed surfaces, such as walls, trenches, and sumps, are usually more cosity to prepare because hand tools are required. Surface preparation also opens up voids and bugholes that must be patched before a coating can be applied. Patching materials generally cost more per gallon than do coatings.

Surface preparation cost can be reduced by avoiding formed surfaces. Loading pads, for example, can be poured with a continuous slope to the edges, eliminating the curb around the perimeter.

Using a light broom finish or finishing concrete with a wooden float will reduce cost over a powered steel trowel finish. Contractors generally charge more for a powered trowel finish, and the resulting surface is too smooth to achieve good coating adherence. More time and labor are required to prepare a powered trowel finish than are required to prepare a finish that is rougher.

Older structures that are contaminated with petroleum or fertilizers will have to be cleaned or 
decontaminated using solvents. Petroleum products interfere with the coating adhesion. Concrete contaminated with UAN solution or other fertilizer salts will need to be removed; otherwise, the concrete will continue to degrade beneath the coating.

Coating Materials Cost: Agrichemical retailers often place too much importance on the cost of coating materials. Products tested by TVA ranged in price from $\$ 45$ to $\$ 100$ per gallon of coating. Most companies offer discounts for larger purchases. For fertilizer and pesticide secondary containment structures, two coats, each being 8 to 12.5 mils thick (total DFT of 16 to $25 \mathrm{mils}$ ) are recommended. With 100 percent solid materials, the least and most expensive combinations, based on the coating costs and thicknesses given above are, respectively, $\$ 0.50$ and $\$ 1.70$ per square foot. Primers can add another $\$ 0.10$ to $\$ 0.20$ per square foot.

Application Cost: The final cost associated with coating installation is the cost of application. Application costs should range from $\$ 0.25$ to $\$ 0.50$ per square foot.

Large, flat surfaces that can be spray applied are less costly. Systems not needing a primer will be less expensive. Areas needing a non-skid finish will be more expensive because of the labor involved in either mixing aggregate or spreading aggregate and removing that which does not adhere to the base coat. Non-skid surfaces are needed in vehicle and foot-traffic areas; otherwise, the coatings become too slick when wet. Aggregates, such as sand or aluminum oxide, also increase the durability of some coating systems. The coating supplier should be consulted regarding the size and type of aggregate to use as well as the application or mixing rate.

Most coatings must be applied to concrete when temperature is above 50 degrees $\mathrm{F}$, and coatings must cure overnight. Some coatings, however, can be applied down to 35 degrees $F$, eliminating the need for supplemental heat. Some coatings cure rapidly enough for two coats to be applied in one day. Shortening the job time by one day can offset a higher coating cost.

By summing the range of costs for mobilization, surface preparation, coating materials, and application, the contracted cost for installing a coating on a typical agrichemical retail secondary containment should be between $\$ 1.50$ and $\$ 5.00$ per square foot.

\section{SUMMARY}

Because of concrete's porosity and, low tensile strength, surface preparation must be done correctly to ensure good coating adhesion. Coating selection should be based on the chemical and mechanical exposure of the concrete. To ensure that the installed coating is free of pin-holes and other defects, two coats, each with a dry film thickness of at least 8 mils, are recommended. Coatings found to be adequate in the study should be able to withstand short periods of pesticide exposure. Exposure to solvent based pesticides for extended periods can cause swelling and softening of these coatings. For prolonged exposure to solvent-based products, coatings found to be excellent should be used.

\section{DISCLAIMERS}

Mention of specific products does not imply endorsement by TVA, nor does it imply criticism of similar products not mentioned.

Due to the variations in the formulation of coatings, results from particular coatings in this study are not necessarily applicable to similar generic coatings not tested. 


\section{REFERENCES}

1. NACE, Book of Standards. 1991. National Association of Corrosion Engineers, Houston, TX.

2. Coatings Technology Institute. 1992. Successful Coating and Lining of Concrete. CTI, P.O. Box 1332, Roswell, GA.

3. ASTM. ASTM Annual Book of Standards. 1992. Section 6, Volume 06.01; Section 8, Volume 08.01; Section 9, Volume 09.01. ASTM, Philadelphia, PA.

4. TVA. Environmental Handbook for Fertilizer and Agrichemical Dealers. 1991. Chapter 4, Containment. TVA Bulletin Y223, TVA Bookstore, Tennessee Valley Authority, Muscle Shoals, AL.

5. Kammel, D.W., G.L. Riskowski, R.T. Noyes, and V.L. Hoffman. 1991. Pesticide and Fertilizer Containment Facilities Handbook (MWPS-37). MidWest Plan Service, Agricultural Engineering, Iowa State University, Ames, IA.

6. Portland Cement Association. 1990. Effect of Substances on Concrete and Guide to Protective Treatments. Portland Cement Association, Skokie, IL.

7. Broder, M.F., D.T. Nguyen, and A.L. Harner. 1992. Effects of Fertilizer and Pesticides on Concrete. ASAE Paper No. 921090. American Society of Agricultural Engineers. St. Joseph, MO.

8. Guide to Sealing Joints in Concrete Structures. Publication No. ACI 504-90. American Concrete Institute, Detroit, MI.

9. Nguyen, D.T., M.F. Broder, C.L. McDonald, and E.A. Zarate. 1994. Performance of Coatings for Concrete Secondary Containment Exposed to Pesticides and Fertilizer. Proceedings from the SSPC 94 Seminars, pp. 129-151. SSPC 94-19. Steel Structures Painting Council, Pittsburgh, PA.
10. Broder, M.F., D.T. Nguyen, and E.A. Zarate. 1994. Performance of Coatings for Concrete Exposed to Pesticides and Fertilizer. TVA Circular Z-354. TVA Bookstore, Tennessee Valley Authority, Muscle Shoals, AL.

11. Fisher, A.O. 1964. Tools and Techniques for Laboratory Corrosion Testing. NACE, Houston, TX.

12. Fisher, A.O., and C.N. Carpenter. 1981. Advances in the Chemical Testing of Elastomers. Materials Performance. Vol. 37, No. 5. NACE, Houston, TX.

13. Farm Chemicals Handbook '92. 1992. Meister Publishing Company. Willoughby, $\mathrm{OH}$.

14. The Agrochemicals Handbook. 1992. Royal Society of Chemistry/Information Services. Thomas Graham House, Science Park, Milton Road, Cambridge, England. 